\title{
Estrategias de «city placement» (emplazamiento de ciudades en el cine) en la promoción del turismo español. El caso de Zindagi Na Milegi Dobara (Sólo se vive una vez, 2011)
}

\author{
Alfonso Méndiz Noguero ${ }^{1}$ \\ Universitat Internacional de Catalunya
}

Recibido: 01/05/2014

Aceptado: 21/05/2014

\begin{abstract}
Resumen
El rodaje de una película en una ciudad puede otorgar a ésta popularidad, imagen internacional, atracción turística y también beneficios económicos. En sentido inverso, la ciudad puede ofrecer a las productoras algunas compensaciones interesantes: permisos especiales de rodaje, filmación en monumentos públicos, vigilancia y seguridad, ayuda en la financiación, exenciones fiscales, etc. Este tipo de estrategias, bautizadas como «city placement», puede considerarse una especificación del brand placement. El estudio de Zindagi Na Milegi Dobara (Sólo se vive una vez, 2011), película hindú rodada en España gracias a un convenio con Turespaña, es un claro ejemplo de «city placement»: el acuerdo suscrito que benefició tanto a la película (facilidades para la producción, ayuda económica, etc.) como a las Comunidades Autónomas en las que se rodó: Cataluña, Valencia, Andalucía y Navarra; y tanto en la economía local (pernoctaciones, restauración, etc.) como en la promoción internacional de su turismo. La metodología empleada para el análisis del «city placement» demuestra dos supuestos: la eficacia de esta nueva técnica y la conveniencia de esa misma metodología de análisis.
\end{abstract}

Palabras clave: emplazamiento de ciudades, películas, ciudades, metodología de análisis, Sólo se vive una vez.

\footnotetext{
${ }^{1}$ Profesor Titular de Comunicación Audiovisual y Publicidad en la Universidad de Málaga. Director del Grupo de Investigación «Nuevas Formas Publicitarias y Nueva Economía» (SEJ 396), se ha especializado en el Product placement, técnica publicitaria sobre la que ha dirigido cuatro Tesis Doctorales y ha publicado diez artículos y un libro que cuenta con 4 ediciones: Nuevas formas publicitarias: Patrocinio, Product placement, Publicidad en Internet (2014, 4 ed.).E-mail: amendiz@uma.es.
} 


\author{
Strategies of «city placement» (placement of cities in movies) \\ in promoting Spanish tourism. The case of Zindagi Na Milegi Dobara (You \\ Don't Get Life a Second Time, 2011)
}

\begin{abstract}
Shooting a feature film in a city can enhance its popularity and international image, attracting tourists and bringing in economic benefits. In return, the city can offer interesting privileges to film production companies: special shooting permits, permission to film at public monuments, vigilance and security, finance, tax exemptions, etc. Such strategies, known as «city placement», can be considered specific brand placement. The study of Zindagi Na Milegi Dobara (You Don't Get Life a Second Time, 2011), an Indian film that was shot in Spain thanks to an agreement with Turespaña, is a clear example of such a positioning of a city. This agreement benefited both the production company (production facilities, financial support, etc.) and the Autonomous Communities in which it was filmed - Catalonia, Valencia, Andalusia and Navarre - by contributing to the local economy (overnight stays, restaurants, etc.) and through the international promotion of tourism. The methodology used for the analysis of «city positioning», proves two hypotheses - mainly, the effectiveness of this new technique and the convenience of the methodology.
\end{abstract}

Keywords: city placement, movies, cities, analysis methodology, Zindagi Na Milegi Dobara.

\title{
1. Introducción, objetivos y método
}

El 15 de julio de 2011 se estrenó en Bombay la película Zindagi Na Milegi Dobara. Contaba la historia de tres amigos hindúes que durante un mes viajan por España en una peculiar «despedida de solteros», y aquí descubren una cultura y una forma de vida que les deslumbra y les cambia la vida. La cinta despertó el interés del público: no en vano, el trío protagonista estaba conformado por tres actores de primera fila: Hrithik Roshan (como Arjun), Farhan Akhtar (como Imraan) y Abhay Deol (como Kabir), actores muy queridos por los espectadores indios: para ellos son lo que Brad Pitt, Tom Cruise y George Clooney pueden ser en Estados Unidos. A este plantel se unía la conocida intérprete Katrina Kaif (en el papel de Laila) y una actriz catalana: Ariadna Cabrol (como Nuria, el único personaje español).

Lo interesante de este caso se había fraguado tiempo atrás, porque este filme, que muestra durante más de dos horas la belleza de muchos enclaves españoles, había sido fruto de un elaborado acuerdo de «city placement» entre la productora (Excel Entertainment) y la delegación en Nueva Delhi de la Oficina de Turismo Español (Turespaña).

El concepto del «city placement» es de reciente creación (Méndiz, 2011), y propone una reorientación de los estudios sobre la influencia del cine en la promoción de una ciudad, que han sido desarrollados desde la perspectiva del turismo desde hace años más de veinte años (Riley y Van Doren, 1992). La propuesta de este concepto supone incluir también la perspectiva de la productora y sus intereses particulares; es decir, reconocer que la influencia se da en los dos sentidos: por una parte, la ciudad obtiene popularidad, imagen internacional, atracción turística y también beneficios económicos (alojamiento, restauración, etc.); por otra, la película consigue también beneficios a cambio: creación del ambiente adecuado (el París romántico y bohemio, la Roma del clasicismo y el arte), la disponibilidad del apoyo material (desde cámaras hasta 
elementos de transporte), la infraestructura técnica y el personal necesario (extras, artistas de $2^{\circ}$ nivel), el apoyo logístico por parte del Ayuntamiento (permisos de rodaje, ofrecimiento de policías y servicio de seguridad) e incluso ayuda económica o exención de cargas fiscales. Se trata, por tanto, de una transacción comercial: te doy porque tú me das, ruedo aquí (y hago que mejore tu economía y el turismo) porque tú me ofreces mejores condiciones para la producción. Por tanto, este fenómeno se basa en el intercambio, y exige ser estudiado en el ámbito del marketing, como un caso específico del product placement.

El objetivo que nos proponemos es doble. Por una parte, analizar un caso relevante de emplazamiento de ciudades: el primero en cuya financiación ha participado Turespaña, y que se planteó como la acción promocional más importante del turismo español llevada a cabo en la India. Por otra, ratificar una concreta metodología de análisis del «city placement» que define los principales indicadores para evaluar, a partir del guión o de la película ya terminada, la eficacia de las apariciones de ciudades en la gran pantalla.

En consonancia con los objetivos, la metodología es también doble. Por una parte, sigue el método propio del «Case study», analizando el origen del proyecto, su desarrollo y su impacto sobre el turismo. Por otra, utiliza -como se ha dicho- un método de análisis del «city placement» que ha sido expuesto en otro trabajo (Méndiz, 2014), y que se enmarca en la metodología clásica del análisis de contenido. Hay un tercer instrumento: la investigación documental de fuentes para evaluar la recepción del filme por parte de los espectadores y de la crítica. Por su propia naturaleza, la mayor parte de esas fuentes son de carácter hemerográfico.

\section{Sinopsis argumental de Zindagi Na Milegi Dobara (2011)}

Tras comprometerse en matrimonio con Natasha, Kabir prepara una despedida de soltero con sus dos amigos de toda la vida: Arjun, un bróker adicto al trabajo, e Imraan, un poeta a escondidas que trabaja como redactor publicitario. Cumple así un pacto que hicieron en el Instituto: el primero en casarse deberá organizar un viaje a un país exótico para realizar tres deportes de riesgo. Y el país exótico es España.

Arjun viaja desde Londres, Imraan desde Bombay y Kabur desde Nueva Delhi. Se encuentran en Barcelona, y allí, mientras el primero continúa con gestiones financieras, los otros dos descubren lo más bello de la Ciudad Condal: la Sagrada Familia, el Arco de Triunfo y, sobre todo, el barrio gótico. Imraan se empeña en visitar las famosas galerías de arte, pues espera hallar alguna pista para encontrar a Salman, su padre biológico, afamado pintor que emigró a España.

El primer destino - tras pasar por Montserrat y El Bruc- es la Costa Brava, donde deberán superar la primera prueba: el submarinismo entre rocas de coral. La instructora resulta ser Laila, una inglesa de origen indio que ayuda a Arjun a superar su miedo a las profundidades. Arjun queda fascinado por la belleza del fondo marino y, al mismo 
tiempo, empieza a sentirse atraído por la monitora. Esa noche cenan juntos y Leila les propone ir a Buñol, donde pueden participar en la Tomatina. Acceden, y la experiencia resulta fascinante. Al grupo de los cuatro se une allí Nuria, una amiga de Laila, con la que Imraan congenia de inmediato. Mientras éste pretende conquistarla imitando el baile flamenco, Arjun da un largo paseo con Laila, y esa conversación le transforma: su filosofía de «matarse a trabajar hasta los 40 y luego jubilarse» se deshace por completo; descubre la importancia de amar, de vivir, de salir de su mundo: de encontrar la verdadera felicidad. A la vez, Natasha, que ha oído hablar de la belleza de las dos chicas que les acompañan, se presenta de improviso en Buñol y tiene allí la primera disputa con Kabir.

Tras dejar a Natasha en el aeropuerto y a las otras dos chicas en Buñol, los tres amigos prosiguen su viaje, ahora por tierras andaluzas. Visitan Ronda, Grazalema y Setenil, y llegan a Sevilla donde realizan la segunda prueba deportiva: lanzarse en paracaídas. Tras una rápida preparación, los tres amigos se lanzan: en la caída, se encuentran, juntan sus manos y esa bella secuencia refleja la profunda unidad entre ellos (amenazada en varias escenas anteriores) y su anhelo de liberación personal frente al cepo que cada uno tiene en su corazón. Esa liberación es experimentada, de modo literal, por Imraan, que vivía dominado por su miedo a las alturas. Para celebrar el descenso, acuden a una fiesta que tiene lugar en la plaza mayor de un pueblo (Alájar) donde presenciamos una larga secuencia coreográfica: el baile más espectacular de todo el filme.

La celebración continúa en un bar, donde entablan una pelea con un desconocido y acaban en la cárcel. Imraan llama por teléfono a Salman, con quien finalmente ha contactado, y éste paga la fianza y les lleva a su casa. En una conversación íntima con Imraan, Salman desvela que nunca quiso tener una vida sedentaria con hijos, por eso le abandonó a él y a su madre. El descubrimiento de quién era en verdad su padre, hunde a Imraan en el abatimiento.

El trío sigue con su aventura y llega a Pamplona, donde se enfrentan -sin ninguna preparación- a la tercera y más peligrosa prueba: correr delante de los toros en un encierro sanferminero. Justo en ese momento, Kabir reconoce a los otros dos que no está preparado para casarse: Natasha ya no es la dulce novia que conoció, sino una mujer tremendamente posesiva; pero no quiere romperle el corazón cancelando la boda. En ese momento, Imraan sugiere hacer un nuevo y definitivo pacto: si salen vivos del encierro, cada uno superará su «miedo» personal y asumirá el reto tantas veces postergado. Cuando estalla el segundo cohete y los toros se les echan encima, los tres experimentarán la definitiva transformación que iniciaron al llegar a España.

\section{3. «Case study»: Gestación del «city placement»}

Entre septiembre y noviembre de 2009, la directora Zoya Akhtar y la co-guionista Reema Kagti redactaron el guión completo de «Running with the bulls» (corriendo tras los toros): la historia de tres amigos hindúes que viajaban por distintas ciudades 
de México en el mes de vacaciones. El guión tenía encanto, pero quedó paralizado por falta de recursos tras varios intentos fallidos de conseguir ayuda del Departamento de Turismo de México.

Habiendo tenido noticia del proyecto, el director de Turespaña en Nueva Delhi, Miguel Nieto-Sandoval, ofreció a la productora unas condiciones inmejorables si la película se rodaba en nuestro país2: asumir una parte del presupuesto y facilitar el rodaje en los lugares de España que desearan. Tras varias negociaciones, el acuerdo se cerró a principios de 2010. Y, con ese cambio de país, el guión original quedó incluso mejorado: conservó toda la magia de la historia y acentuó la fuerza dramática de dos secuencias clave: la corrida delante de los toros -más significativa en los Sanfermines de Pamplona-, y la fiesta popular nocturna, más espectacular y folclórica en el marco de un tablado flamenco.

Como señala Fernando Casas, uno de los gestores del acuerdo, «la razón por la que esta película ha cuajado con tanto éxito en el tejido cultural de los indios es que España tiene culturalmente similitudes con la India. Por un lado está todo el legado musulmán-Andalusí en el caso español y Mogol en el caso de la India-, la arquitectura y monumentos, etc. Los sanfermines de algún modo recuerdan a ciertas fiestas populares del Sur de la India, donde lanzan toros a correr y los tumban a caballo. El flamenco es una cultura que a los indios les atrae, tanto musicalmente como por las costumbres gitanas arraigadas en la cultura flamenca» (Grijalva, 2012).

Con el acuerdo firmado, comenzó la contratación de actores, y en junio de 2010 empezó el rodaje en España. Durante casi tres meses el equipo grabó escenas en 4 Comunidades Autónomas con toda la ayuda de los gobiernos locales, que sabían que este filme podía promocionar el turismo en su territorio. Primero filmaron en Cataluña: Barcelona (barrio gótico y diversos monumentos emblemáticos); la costa Brava (las playas cristalinas y las tomas bajo el agua); y Montserrat, con sus montañas agrestes. Luego, en la Comunidad Valenciana: Cheste, Benidorm, Buñol, alrededores de Valencia y diversos lugares de la costa levantina. Más tarde en la Comunidad navarra: durante cinco días filmaron en Pamplona un gigantesco simulacro de los sanfermines, y en días posteriores, planos abiertos en los alrededores de Olite y en el desierto de las Bardenas Reales. Finalmente, se dirigieron a Andalucía, donde grabaron en Carmona, Ronda, Setenil de las Bodegas, Grazalema, Alájar y Riotinto, además de rodar en diferentes carreteras de Sevilla, Cádiz y Huelva, y tomar imágenes aéreas en Ronda y Zahara de la Sierra.

${ }^{2}$ En una entrevista, Nieto-Sandoval atribuye la iniciativa a la productora: «Cuando el productor tuvo la película en mente, nos explicó el proyecto y nos pidió ayuda, algo que hemos hecho al proporcionarles apoyo logístico y económico» (Torres, 2011). En otro artículo, sin embargo, fuentes de Turespaña asumen la iniciativa: «El Gobierno español, por medio de su ente público Turespaña, llegó a un acuerdo con la productora del filme Excel Entertainment, por el cual el gobierno prestó una ayuda económica a cambio de promocionar la imagen de España» (Girjalva, 2012). 


\section{Impacto del filme en el turismo indio}

La película Zindagi Na Milegi Dobara cosechó un éxito enorme. La expectación levantada motivó que se estrenase en 2.500 salas. Fue la película hindú más taquillera del año, y recaudó más del doble que el gran hit del verano: Harry Potter y las reliquias de la muerte (2011). Al final de su recorrido, había sido vista por más de 70 millones de indios, que dejaron en taquilla $27^{\prime} 85$ millones de dólares (la $20^{\mathrm{a}}$ película más taquillera de toda la historia de su país). Luego llegaron los galardones. En la entrega de los premios Filmfare, considerados como los «Óscars de Bollywood», se convirtió en la gran triunfadora, con 7 importantes distinciones: mejor película, mejor director, mejores diálogos, mejor actor de reparto, mejor película para los críticos, mejor fotografía y mejor coreografía musical.

Con este precedente, Turespaña confiaba en que tuviera un fuerte impacto sobre el turismo hindú. Y así fue. Hasta 2010, los turistas indios que anualmente viajaban a España eran aproximadamente 70.000 , pero en el año de su lanzamiento (2011) aumentaron a 110.000 , y en el año siguiente, a 140.000. Además, algunas escenas de la película se convirtieron en referente cultural para futuras planificaciones de los turoperadores. Esas secuencias fueron:

1) La Tomatina de Buñol. Sin duda, fue la secuencia más recordada por los espectadores hindúes. Filmada en el mismo lugar donde tiene lugar la fiesta levantina, más de 500 figurantes se arrojaron durante dos días 16 toneladas de tomates, que habían sido comprados en los alrededores de Buñol y en Portugal. El resultado dejó, ya de forma inmediata, cuantiosos beneficios para la ciudad. Como señalaba un representante del Ayuntamiento: «Es una gran experiencia, da dinero para el pueblo, para los jóvenes que están en la figuración, para los agricultores de tomate, para quienes ponen las lonas... En general, el pueblo sale ganando» (Navarro, 2011).

Además, y como resultado de la filmación, la Tomatina fue noticia en Nueva Delhi durante varios días. El diario Bollywood Hungama publicó un reportaje especial sobre esta fiesta española, y en él recogía estas palabras de la directora Zoya Akhtar: «La Tomatina en España es un festival más cercano a nuestro Holi ${ }^{3}$. Juegan con los tomates y el mundo se vuelve de color rojo en ese día. La energía es contagiosa y la escena es un regalo para la vista. Nos lo pasamos genial rodando esta secuencia. Pero no todo fue color de rosa: fue una pesadilla logística para el productor. Rodamos en el mismo lugar donde la fiesta realmente se lleva a cabo y tuvimos que cerrar el centro de la ciudad. Los vecinos de Buñol fueron muy amables y, de este modo, celebraron la Tomatina el año pasado dos veces... una vez para España y otra vez para la India» (Bollywood Hungama, 19.III.2011).

El resultado fue que el 31 de agosto de ese año (la fiesta de Buñol se celebra siempre el último miércoles de agosto) varias decenas de turistas hindúes se presentaron por

\footnotetext{
${ }^{3}$ El Holi es una fiesta que los indios celebran durante la primavera y en la que los asistentes se arrojan pintura unos a otros.
} 
primera vez en la Tomatina, y esto fue también noticia en su país. Además, y por la semejanza con su fiesta del Holi, se organizaron «Tomatinas» en diversas ciudades hindúes; en la de Nueva Delhi participaron más de 15.000 asistentes (Grijalva, 2012). En 2012, los turoperadores ofrecieron viajes a España que incluían la estancia en Buñol durante esa fiesta.

2) Alájar y la canción «Señorita». La secuencia más vistosa del filme es un baile con una inmensa coreografía que tiene lugar en un pueblo típicamente andaluz, en una noche de fiesta. Se rodó en Alájar (Huelva) durante cuatro noches seguidas. Para ese pueblo de 800 habitantes ha sido el evento más importante de la década. En él participaron 300 extras, de Alájar y alrededores, con la alcaldesa Carmen Osorno a la cabeza. El rodaje fue noticia en los principales diarios españoles y en varias publicaciones hindúes. En Internet se pueden ver aún más de 18.000 referencias a la filmación de esa secuencia. Como resultado, el número de visitantes a ese pequeño pueblo andaluz empezó a crecer ese mismo verano (Moya, 2010).

Lo más importante fue que la canción que se oye y se baila en esa secuencia, «Señorita», fue un auténtico boom en la India. A los pocos días del estreno del filme, el tema que los protagonistas bailan al más puro estilo indio -y que es una mezcla entre la rumba y el Bollywood más genuino- se convirtió en la canción del verano. Las radios la ponían una y otra vez, las discotecas la reconocieron como la balada más demandada, y la gente la bailaba por las calles a todas horas. Entró directamente en el top ten de las canciones más vendidas, y la cantaora gaditana que puso la voz, María del Mar Fernández (absolutamente desconocida en España), pasó a ser la cantante española más conocida en el país. Ella comentaba en una entrevista: «Fíjate qué curioso que conocen allí mi voz y mi nombre millones de personas y, sin embargo, no saben qué cara tengo» (Mazón, 2011). En menos de un mes, la canción recibía más de tres millones de visitas en Internet, y en los foros en la red miles de indios pedían la traducción de las partes cantadas por ella en español, y pedían que acudiera a cantar a la India.

El broche de oro llegó con los premios Filmfare. El galardón a la «mejor coreografía musical», convirtió a esta secuencia en la tarjeta de presentación del filme, con lo que Andalucía pasó a ser para los indios un lugar festivo y maravilloso que todos deberían visitar algún día.

3) El encierro de los Sanfermines. La secuencia más larga e intensa del filme es la carrera de los tres protagonistas durante un encierro sanferminero. Allí experimentan -todos, pero especialmente uno de ellos- la definitiva transformación de sus vidas, iniciada el mismo día en que pusieron pie en suelo español.

El rodaje duró cinco días y contó con la ayuda de Turespaña para filmar en unas condiciones muy ventajosas. El 14 de julio de 2010 terminaban los sanfermines, pero el Ayuntamiento, por intervención de Turespaña, decretó que no se retiraran los 2.800 tablones que componían el vallado de su recorrido: se dejaron puestos para que la 
productora hindú pudiese grabar las escenas de la película en los días siguientes, en el mismo lugar de los encierros. Además, cerró las calles de todo el recorrido y actuó como intermediario con los comercios que tuvieron que cerrar durante esos cinco días. De hecho, la productora recompensó a cada establecimiento con 400 euros por día de filmación (Urieta 2010). Por último, reunió a un grupo de expertos que contribuyeron a dar mayor verosimilitud a las escenas y mayor seguridad a la filmación. La Cruz Roja Navarra, a petición del alcalde, destacó a 20 de sus voluntarios para que esos días atendieran a los heridos o contusionados como consecuencia de las tomas.

Todo esto lo hacía el consistorio, evidentemente, pensando en los beneficios que la película podía reportar a la ciudad. De hecho, en un comunicado que hizo público antes de comenzar el rodaje, subrayaba que el filme «contribuirá a promocionar internacionalmente la capital navarra y sus fiestas de San Fermín, con una imagen cuidada y verosímil del encierro, al ser rodada en su escenario natural y con la ayuda de asesores locales» (Dianaji, 2010).

En efecto, la película ha despertado el deseo de los indios de visitar Pamplona y participar en los sanfermines. En la India se venden paquetes turísticos para visitar España, que incluyen todo el itinerario de los sanfermines. El gestor de viajes Luis Arellano, contratado por la productora para las localizaciones en Navarra (Olite y desierto de las Bardenas Reales), ofrece en Nueva Delhi un paquete denominado «Zindagi tours»: recorridos Zindagi, es decir, recorrido por los lugares de la película. $\mathrm{Su}$ agencia Spain Asia Travel, que organiza viajes India-España en ambas direcciones, ha visto crecer rápidamente el número de demandas hacia nuestro país a raíz del estreno de la cinta (Torres, 2010).

Además, el rodaje tuvo un efecto inmediato en la economía local. Más de 400 figurantes navarros fueron contratados para las secuencias, así como carpinteros, decoradores, iluminadores y sastres (hacían falta vestidos para corredores, policías, etc.) y asistentes de producción en los distintos tramos. Previamente, Excel Entertainment había contratado a una productora local para que grabara escenas reales durante los encierros de ese año, con tomas desde el vallado y los balcones circundantes. También contrató a una ganadería de Jaén para disponer de diez mansos que simularon ser los temidos astados que vemos en el filme.

\section{Balance global del acuerdo de «city placement»}

Estos tres casos que hemos analizado evidencia que el filme presenta casos notorios de «city placement», donde el beneficio se obtiene por ambas partes: productora y ciudad emplazada. Gracias al acuerdo con Turespaña, Excel Entertainment consiguió muchas facilidades para rodar en España: una cuantiosa ayuda económica, que no ha sido desvelada (Grijalva, 2012); permisos de rodaje en los lugares más emblemáticos, donde nunca hubiera conseguido rodar; colaboración institucional para cerrar durante días las calles y las plazas que necesitaban (Ayuntamientos de Buñol, de Barcelona, de Lloret de Mar, de Alájar, de Pamplona); colaboración de expertos y asesores, etc. 
Por su parte, España consiguió una presencia destacada en un filme con grandes actores, alto presupuesto, 7 premios Falmfire y una previsible gran difusión. Difusión en India, un país con 1.200 millones de habitantes (en el que la mayoría suele ver películas nacionales con gran frecuencia y marcado entusiasmo), y también en los países donde se ha estrenado: sólo en Estados Unidos, ha tenido más de 3 millones de espectadores. Además, es un filme que no sólo da una bella imagen de nuestro país, sino que le da personalidad y carisma. En palabras de Shravan Ghalla, Secretario General de la Asociación India de Tour Operadores: «Antes de la película la gente en la India sólo sabía que España era un país, otro más; sin embargo, tras la aparición de Zindagi Na Milegi Dobara, muchos han comenzado a hablar de España, España y España» (Torres, 2010).

Al margen del turismo que pueda atraer, la película ha dejado aquí una fuerte suma de dinero. En cada una de las Comunidades Autónomas (Cataluña, Valencia, Andalucía y Navarra), la producción ha grabado escenas masivas, que han requerido entre 300 y 500 figurantes durante varios días; ha necesitado bailarines, peluqueros, sastres y un largo etcétera de trabajadores en los más diversos sectores, y a lo largo de todo el rodaje ha contado con más de ciento cincuenta técnicos y auxiliares. Durante tres meses contrató diariamente más de un centenar de pernoctaciones y comidas, lo que supuso un fuerte impulso en los sectores de hostelería y restauración. Según datos ofrecidos por Turespaña, el 90 por ciento del presupuesto del filme se ha gastado en España, y el 75 por ciento del equipo técnico ha sido español.

\section{Análisis del «city placement» en Sólo se vive una vez}

Como ya se dicho, en otro lugar (Méndiz, 2014) se ha propuesto una metodología de análisis del «city placement» que ahora nos proponemos refrendar a través de un análisis global de los emplazamientos en el filme. La metodología utilizada se articula en torno a tres ámbitos:

- Los aspectos visuales y/o verbales, que determinan el reconocimiento de la ciudad y su fijación en la memoria del espectador. Siguiendo a Villafañe (1992), se han definido cinco indicadores de la visibilidad y verbalidad del lugar emplazado.

- Los aspectos psicológicos, que facilitan la creación de una «imagen mental» del lugar o establecen una relación afectiva entre el espectador y la ciudad. Teniendo en cuenta los aspectos que afectan al procesamiento de la información en nuestro cerebro (Puente, 2003), proponemos también cinco indicadores.

- Los aspectos narrativos, que envuelven al espectador en la historia, los personajes o los temas que se desarrollan en el enclave o lugar. En este apartado, los indicadores se han fijado atendiendo a los autores más destacados sobre el guión audiovisual (McKee, 2009; Seger, 2010).

Previamente, realizaremos una identificación de las principales ciudades o lugares turísticos emplazados en la película. 


\subsection{Ciudades o lugares emplazados en el filme}

Al margen de pueblos o paisajes que aparecen de forma más o menos tangencial, podemos identificar siete zonas geográficas que aparecen en la cinta con identidad propia:

1. Barcelona: dentro de ella, podemos ver algunos lugares típicamente turísticos (estatua de Colón, Arco de Triunfo, Sagrada Familia), un negocio de restauración con mucha solera (Hotel Casa Fuster, de estilo modernista, donde transcurre una larga escena con diálogos) y el barrio gótico (la Catedral, la Iglesia de Santa María del Mar, la plaza de Santa María y el Paseo del Born: es decir, la esencia del gótico catalán).

2. Costa Brava: en el filme se habla de la «Costa Brava» como lugar genérico y se muestran imágenes de sus playas y acantilados. Se rueda, sobre todo, en Lloret de Mar, donde tiene lugar la primera aparición de Laila y las bellas escenas del buceo de los protagonistas: las imágenes del fondo marino, de cuidada fotografía, dan una idea de lugar mágico y suscitan el deseo de practicar allí el submarinismo.

3. Montserrat y El Bruc: es una aparición breve, pero claramente reconocible, y en dos tiempos: primero el macizo rocoso de Montserrat, la montaña más importante y característica de Cataluña, y después una gasolinera en El Bruc. En ambas transcurren escenas con diálogo que involucran a los protagonistas.

4. Buñol y la Tomatina: larga secuencia, con más de 400 extras, que muestra la alegría y el colorido de esta típica fiesta levantina. Rodada en el mismo lugar donde se celebra, toda ella es un reclamo turístico. Sin duda, una de las secuencias más recordadas y, a la vez, más identificadoras de nuestro folclore festivo.

5. Andalucía y el flamenco: en tres secuencias diferentes (Valencia, Alájar y carreteras andaluzas) se refleja de forma nítida el carácter del pueblo andaluz y la peculiaridad de sus fiestas; muy especialmente, el atractivo del cante flamenco. A diferencia de los anteriores lugares, aquí no se emplaza una ciudad concreta (aunque se mencionan varias: Sevilla, Grazalema, etc.), sino que lo emplazado es Andalucía misma: su estilo de vida y su cultura; una cultura que se aprecia en los bailes flamencos, en los vestidos de faralaes, en la gastronomía y, sobre todo, en el «carácter andaluz». Además del gran baile («Señorita») en Alájar, se rodaron también escenas en Aracena y Riotinto, en la carretera A-61 (rotonda El Abanico y el mirador de Cerro Colorado), y el trayecto donde se encuentra el pantano Gossan-Cobre, cerca de Campofrío.

6. Ronda, Grazalema y Setenil de las Bodegas: esta zona geográfica sí es presentada como un lugar con identidad propia. Vemos primero unas tomas aéreas de Ronda, con el Puente Nuevo sobre el Tajo, para seguir después una conversación íntima de los protagonistas por distintas calles de Ronda, Grazalema y Setenil de las Bodegas, presentadas en el filme como una misma localidad. Vemos carteles que señalizan esos pueblos, y una arquitectura muy característica de la zona: 
el trazado urbanístico típicamente andalusí, con estrechas calles serpenteantes empedradas con guijarros; el blanco característico de las fachadas encaladas en contraste con los tejados de teja roja, las rejas de forja en ventanas y balcones, y el alegre colorido de las macetas de flores en los alféizares; un conjunto al que se une el verde de la sierra y el azul del cielo.

7. Pamplona y los Sanfermines: la escena cumbre, el clímax de la película y la resolución final de la historia, acontecen en Pamplona durante los sanfermines. Además de los famosos tramos del recorrido (Cuesta de Santo Domingo, Calle Mercaderes, Calle de la Estafeta) la película muestra tomas cercanas desde los balcones y desde distintos puntos del vallado. También hay una larga secuencia en el mítico Café Iruña, y planos largos de la comparsa de Gigantes y Cabezudos.

A continuación, llevaremos a cabo el análisis de las ciudades emplazadas, siguiendo el esquema metodológico descrito. En cada uno de los tres apartados (aspectos visuales y/o verbales, aspectos psicológicos y aspectos narrativos) hemos señalado cinco indicadores para evaluar su potencial comunicativo y persuasivo.

\subsection{Aspectos visuales y/o verbales (Memoria y reconocimiento)}

1. Tiempo de visión. Este indicador suele ser bastante elevado en los siete casos analizados: 3 minutos en las calles de Barcelona, 17 en las playas de la Costa Brava, 5 en la Tomatina de Buñol; 2 en los exteriores de Ronda, Grazalema y Setenil de las Bodegas; 6 en la canción y baile de «Señorita» en Alájar; y 12 en Pamplona (Café Iruña, Ciudad de Pamplona y, sobre todo, los encierros de San Fermín).

2. Fijación textual. Existen numerosos rótulos y otros elementos de fijación textual que ayudan al recuerdo del lugar visto en pantalla. Sucede prácticamente en todos los lugares emplazados: carteles en el propio aeropuerto de Barcelona, cartel de autopista en la Costa Brava, rótulo bien visible en la gasolinera de Montserrat («EL BRUC»), carteles de carretera en Valencia y Buñol, cartel de fiestas en la Tomatina de Buñol, indicadores en la Sierra de Grazalema (señalando hacia Ronda, Grazalema, Algodonales, etc.), señalización a la entrada de Sevilla y de Pamplona, etc. Todos y cada uno de los nombres de los lugares han querido ser expresamente fijados para facilitar la identificación y memorización por parte del espectador.

3. Apoyo visual. Se constata un fuerte tratamiento visual en todas las ciudades; sobre todo, en el tratamiento de la luz, que realza la mayoría de las «imágenes postales» que la película ofrece. Esto se aprecia sobre todo en las playas de la costa Brava (en las tomas aéreas y en las cuidadas imágenes submarinas), en las tomas de Buñol (con el juego de colores y el ralentí) y en los sanfermines de Pamplona; en esta última juegan también un papel relevante otros elementos de la fotografia: el encuadre, la perspectiva y el montaje subjetivo. Junto a las visiones diurnas, las nocturnas están llenas de emoción y folclorismo, y dan siempre un tono acogedor a las secuencias: la cena en Lloret de Mar, el paseo 
nocturno de Arjun y Laila en Buñol, y el gran baile coreografiado de «Señorita» en Alájar. Todos los lugares emplazados causan en el espectador una impresión positiva y agradable gracias, en parte, a la esmerada fotografía, que embellece todas las estampas más o menos turísticas.

4. Imagen reconocible. El reconocimiento de los lugares se ha facilitado al máximo, pues se buscan siempre emplazamientos típicos o monumentos «icono» de la ciudad escogida: como la Sagrada Familia en Barcelona, el Puente sobre el Tajo en Ronda, la Cuesta de Santo Domingo en Pamplona, etc. Esa apuesta por la «imagen memorable» facilita que el espectador pueda reconocer después el lugar en los folletos, fotografías, libros o vídeos que vea sobre nuestro país. En este sentido, la película abunda en «imágenes tópicas» e «imágenes postales».

5. Explicación. En este filme prevalece la imagen sobre la palabra, pero esto no es óbice para que, además, muchas ciudades reciban una explicación verbal de su cultura o sus costumbres. En el paseo por Barcelona, Kabir menciona expresamente la Catedral como lugar emblemático de laciudad. En la Costa Brava, Arjun comenta tras el buceo que «fue una experiencia mágica; me sentí en el lugar más tranquilo de la Tierra. Fue hermoso. ;Gracias por llevarme!». Y esa misma noche, cuando Laila menciona la posibilidad de ir a la Tomatina de Buñol, surge este rápido diálogo: «¿Tomatina? ¿Qué es eso?». "¡Arjun!, ¿cómo puedes no saber que la Tomatina es la mayor guerra de tomates del mundo? Es como nuestro Holi, pero con tomates». Ya en Buñol, la amiga española del grupo, Nuria, explica a los tres amigos cómo se participa en esa fiesta: «Hay dos reglas. Una, tenéis que dejar pasar a los camiones; y dos, debéis aplastar los tomates antes de lanzarlos; de lo contrario, duele». Finalmente, en Pamplona, Arjun detalla a los otros dos el sentido de los cohetes al comenzar el encierro: «El primer cohete indica que las puertas del corral se han abierto. El segundo, que los toros vienen hacia nosotros. Corremos con el segundo, ¿OK?». Esas frases, que el argumento no precisa en absoluto, reflejan un deseo deliberado de explicar al público hindú nuestra cultura, nuestro modo de ser y el sentido de algunas de nuestras fiestas.

\subsection{Aspectos psicológicos (Procesamiento de la información e Implicación)}

1. Percepción: todas las ciudades emplazadas en la película son vistas por el espectador con nitidez y claridad; habitualmente, en plano destacado y con tiempo suficiente para que pueda captar todos los detalles; en cualquier caso nunca son tomas fugaces, o en las que la ciudad queda en el fondo: el barrio gótico en Barcelona, las imágenes submarinas de la Costa Brava, la guerra de tomates en Buñol, la toma aérea de Ronda... De modo general, podemos concluir que la percepción de la ciudad se ha facilitado siempre lo más posible al espectador.

2. Atención: de cada ciudad se han escogido los lugares más vistosos y atractivos, los que llaman fácilmente la atención del público. Así sucede en las primeras tomas de Barcelona (Villa olímpica, Arco de Triunfo) y en el paseo por el gótico 
catalán; también en las playas de la Costa Brava y en la vista de Montserrat; pero el atractivo de la imagen sube muchos enteros en la plasmación visual de la Tomatina y en el encierro sanferminero: en ambas secuencias, a la brillantez de la imagen se unen el ralentí -que enfatiza los sentimientos de los personajes-, el montaje dinámico y subjetivo, la música de fondo y la expresión (de alegría o de aventura) en el rostro de los personajes.

3. Folclorismo: varias escenas despiertan el interés por la cultura española, en varios ámbitos. Primero, en los monumentos, ya mencionados anteriormente. Después, en la gastronomía: en un bar de copas de Barcelona se mencionan las «tapas de croquetas y tortillas»; en la Costa Brava vemos cómo se prepara una paella, después se menciona este plato español en el diálogo, y finalmente vemos cómo lo degustan. Más tarde, en los bailes y canciones: en el tablado flamenco de Valencia, en la imitación del baile flamenco por parte de Imraan (para así conquistar a Nuria), y, muy especialmente, en el inmenso baile coreografiado de «Señorita». También en las decoración festiva: en el ambiente de la Tomatina y en la fiesta flamenca de Alájar, con sus luces, sus farolillos y su alegre decoración de la Plaza Mayor, y con los vistosos trajes típicos: de lunares, de faralaes, etc. Y, finalmente, en las continuas referencias al modo de ser y de divertirse de los españoles.

4. Implicación: a través de los protagonistas, el espectador hindú puede identificarse con nuestra tierra, que tan hermosamente aparece en pantalla; puede entender, sobre todo, que España es un país en el que puede tener experiencias maravillosas. Como señalaba el Director de Marketing de Turespaña: «La película muestra perfectamente el mensaje que nosotros queríamos dar de la marca España: 'España es el lugar donde te pasan cosas'. Cosas buenas, positivas, divertidas. En la película hay emoción, pasión, life-style. Eso es lo que queríamos que se viera, y eso es lo que aparece» (Torres, 2010).

5. Significación: casi todas las ciudades emplazadas adquieren una significación concreta en el filme. Barcelona es la ciudad artística, gótica y cosmopolita. La Costa Brava tiene playas cristalinas donde el baño y, sobre todo el buceo, se convierten en una experiencia única. Buñol es la ciudad de la fiesta y de la Tomatina. Ronda y Grazalema, el lugar de la paz y el reposo. Alájar, la más pura esencia del flamenco. Y Pamplona, la emoción y la aventura de los sanfermines.

\subsection{Aspectos narrativos}

1. Tensión argumental: Es llamativo que en todos los escenarios emplazados suceden cosas importantes para la historia. En el aeropuerto de Barcelona tiene lugar el primer encuentro de Arjun y Kabir después de años de no verse; en el Hotel Casa Fuster, la reunión de los tres amigos y la planificación del viaje; en el barrio gótico, la primera pista para que Imraan encuentre a Salman Habib, su padre biológico. En el trayecto hacia la Costa Brava se enmarca el enfado entre Arjun e Imraan, que abre viejas heridas no cicatrizadas. En Lloret de Mar superan la primera prueba deportiva: la inmersión submarina (Arjun vence el 
miedo a zambullirse bajo el agua); y también conocen a Laila, que cambia el sentido del viaje y, más tarde, la vida de Arjun. En Buñol acontece la primera disputa entre Kabir y su novia (lo que le hace dudar de su compromiso con ella), y también una larga conversación entre Laila y Arjun: el inicio de su romance. En Ronda, Imraan habla explícitamente de su deseo de ver a Salman Habib, y en contra del parecer de Arjun, conduce en dirección a Sevilla en vez de ir hacia Grazalema. En Sevilla superan la segunda prueba: los tres se lanzan en paracaídas (e Imraan vence el miedo a las alturas). En Alájar tiene lugar el baile fascinante que marca la definitiva integración de los tres en la cultura española; poco después, se sitúa allí la pelea en el bar, el ingreso de los tres en la cárcel y el encuentro de Imraan con su padre. Finalmente, en Pamplona acontece la tercera y más difícil prueba: la aventura y el riesgo del encierro, donde cada uno de los tres está a punto de ser embestido por un toro, y donde los tres experimentan su «redención personal».

2. Impacto emocional: A la vez que suceden cosas importantes para la historia, en cada lugar sobreviene un punto de giro en la subtrama de cada uno de los personajes. En la galería de Barcelona, Imraan descubre la pintura de su padre; en el buceo de la Costa Brava, Arjun «se redime» y cuestiona su filosofía de «matarse a trabajar hasta los 40 y luego jubilarse»; en Buñol, Imraan y la española Nuria descubren un amor apasionado que supera las diferencias de lengua y cultura; mientras, Arjun y Laila descubren un amor que les obliga a transformarse y a olvidar su sentido de independencia; y, también allí, Kabir se siente defraudado por su posesiva novia Natasha (tres historias de amor que hacen crisis en el mismo lugar). En Ronda, Imraan se siente invadido por la nostalgia y «necesita» interiormente encontrarse con su padre; en Sevilla Imraan descubre quién es ese padre al que tenía idealizado; en Pamplona, Kabir reconoce al fin que el matrimonio concertado con Natasha le angustia, y comprende que no tiene sentido continuar ese compromiso. También en Pamplona, durante el clímax de la película, los tres amigos enfrentan en el encierro sus miedos respectivos: al enlace matrimonial, en el caso de Kabir; al sacrificio del éxito profesional, en el caso de Arjun; a mostrar su talento poético, en el caso de Imraan.

3. Fuerza temática: Aunque no en todas, también en muchas ciudades se desarrolla algún tema concreto del filme, en consonancia con las subtramas que hemos analizado. En Barcelona, Ronda y Sevilla, se alude a la búsqueda de la propia identidad (Imraan). En la Costa Brava, a la superación de los propios miedos (simbolizado en el buceo de Arjun) y al necesario equilibrio entre éxito profesional y personal (también Arjun). En Buñol, al atrevimiento personal para iniciar nuevas relaciones (sugerido en el «atrevimiento» de participar en la Tomatina) y al descubrimiento de un amor que cambia las expectativas de la propia vida (Arjun e Imraan). En Alájar, se visualiza la alegría de la fiesta y la experiencia de un encuentro intercultural (Imraan, Arjun y Kabir). Y en Pamplona, la valentía para afrontar o rechazar un compromiso radical (Kabir).

4. Ambiente o estilo: Varias escenas que involucran a ciudades muestran un toque de estilo personal. Un caso emblemático es Barcelona, que se nos muestra como 
una ciudad con identidad artística: al principio, vemos el famoso mural de Miró, icono del aeropuerto barcelonés; más tarde, la secuencia en el barrio gótico, que posiciona a la Ciudad Condal con una referencia histórica; y finalmente, la galería de arte moderno, que vincula su identidad artística a la tradición cubista. Otro caso destacado es el mencionado baile en Alájar: ahí queda reflejado el «ambiente» y la esencia del flamenco, no sólo en la música (una rumba muy andaluza) y en las palmas y los instrumentos (guitarras, castañuelas, cajón flamenco), sino en los trajes, en el tipo de baile, en la decoración y los farolillos; y también en los carteles de fiesta, en los abanicos y hasta en los edificios (encalados y con rejas).

5. Refuerzo musical: Todas las escenas que emplazan ciudades tienen una banda sonora muy cuidada para enfatizar lo que muestra la imagen: monumentos y ambientes. Así, por ejemplo, la música realza el ambiente artístico en Barcelona, la sensación de quietud en Ronda, la sensación de aventura y reto personal en el encierro de San Fermín. Hay, además, dos momentos musicales, con canción y coreografía, que refuerzan la impresión en el espectador. La primera es la Tomatina de Buñol, que se prolonga durante más de 4 minutos. En ella, la explosión visual de imágenes y el sentido de diversión que expresan (un momento clave para la catarsis personal de los tres amigos) se enriquecen con la canción que se oye y se baila: Ik Junoon (Píntalo de rojo). Esta secuencia resulta tan decisiva en el conjunto del filme, que el videojuego que se lanzó en India para promocionar la película tenía como tema principal la Tomatina y la canción que allí se escucha (Robledo, 2011).

La otra gran secuencia es, por supuesto, la del baile «Señorita» en la plaza del pueblo de Alájar. Ya hemos comentado que esa música fue un auténtico boom en la India: se ponía en la radio a todas horas y se bailaba con fruición en las discotecas. Incluso ganó el premio Filmfire a la mejor coreografía del año. Ahora queremos subrayar-es lo más importante- que el espectador descubre en ella un estilo de música y un sentido de la diversión que encajan perfectamente con su cultura hindú (Martin, 2011). En la canción se mezclan ritmos flamencos con el baile típico de las películas de Bollywood (un baile generalmente grupal y coreografiado, que fusiona la danza clásica india, las danzas folclóricas del país, el jazz, el hip-hop y la salsa). La mezcla e hibridación de culturas se advierte hasta en la misma letra de la canción, compuesta con estrofas en español y estrofas en indi.

\section{Conclusiones}

El estudio de Zindagi Na Milegi Dobara (Sólo se vive una vez, 2011) ha servido para dos cosas: por una parte, mostrar la eficacia de un «city placement» bien planificado por ambas partes: productora y lugar turístico; por otra, ratificar la conveniencia de la propuesta metodológica escogida (Méndiz 2014). Con respecto a lo primero, cabe destacar que el filme ha sido el más taquillero del año (fue visto por más de 70 millones de hindúes) y su incidencia en el turismo indio en nuestro país resultó enormemente efectivo: en dos años, se ha duplicado el número de visitantes. Con respecto a lo segundo, 
vemos que ese esquema metodológico sintetiza los aspectos más promocionales de una ciudad emplazada en el cine.

La película refleja y define 7 ciudades o zonas geográficas: Barcelona (barrio gótico, Arco de Triunfo, Sagrada Familia); Costa Brava (playas cristalinas, Lloret de Mar, lugar idóneo para el submarinismo); Montserrat y El Bruc (paraje agreste, típico de Cataluña); Buñol y la Tomatina (la fiesta más exótica y divertida); Andalucía y el flamenco (cultura folclórica con identidad propia); Ronda, Grazalema y Setenil (lugar de paz, pueblos blancos, belleza rural); y Pamplona y los sanfermines (emoción, riesgo y aventura). De ellas, las que mayor impacto han producido en el turismo son estas tres:

1. Tomatina de Buñol. El rodaje de esa secuencia precisó 500 figurantes y 16 toneladas de tomates, lo cual generó ingresos importantes en la economía local. Al mismo tiempo, despertó el interés de los indios por la Tomatina: el mismo verano de su estreno acudieron turistas hindúes por primera vez. Además, se hicieron réplicas de esa fiesta en diversas ciudades de la India, y el videojuego que se lanzó para promocionar la película tenía como tema central la Tomatina.

2. Alájar y la cultura andaluza. En Alájar (Huelva), pueblo de 800 habitantes, se rodó una gran escena de baile y coreografía. Esta filmación fue el acontecimiento de la década, porque requirió la participación de 500 extras durante 4 días y alojó a un equipo técnico y artístico de 150 personas durante casi una semana. Además, fue noticia nacional e internacional, con reportajes de Alájar en algunas revistas hindúes; desde entonces, el número de visitantes no ha dejado de crecer. Por si fuera poco, la canción que se escucha en la secuencia («Señorita», cantada por una cantaora andaluza) ganó el premio Filmfire (los Oscars de Bollywood) a la mejor coreografía y se convirtió en la canción del verano. Las radios la ponían constantemente y la gente la cantaba y bailaba en las discotecas.

3. Los sanfermines. En Pamplona se rodó el clímax de la historia: un encierro de los sanfermines que transforma la vida de los tres protagonistas. Se rodó en el mismo lugar y con los mismos vallados del recorrido, pues el ayuntamiento no los retiró para que pudieran filmar la secuencia. Además, el consistorio reunió a un grupo de asesores para dar a la filmación mayor credibilidad y consiguió el apoyo de la Cruz Roja para la atención sanitaria. A cambio, los encierros se han convertido en una fiesta enormemente atractiva para el turista hindú, y ya se ofrecen «Zindagi tours» que recorren los lugares de Navarra donde se ha filmado la película.

Es, con mucho, la acción promocional más importante del turismo español que se ha llevado a cabo en una película. Su efecto en la economía y en el turismo evidencian la eficacia de esta nueva técnica de comunicación comercial. 


\section{Bibliografía}

DiAnaJI (2010): «Rodaje en Pamplona de la película india 'Zindagi Milegi Na Dobara'», Bollyweb, 17.VII.2010, http://bollyweb.wordpress.com/2010/07/17/rodaje-enpamplona-de-la-pelicula-india-zindagi-milegi-da-dobara/ [consultado el 19/12/13]

GriJalva, S. (2012): «Bollywood y la magia del turismo». El Mundo, 7.X.2012, http:// www.elmundo.es/elmundo/2012/10/05/cultura/1349432043.html [consultado el $18 / 12 / 13]$

Martin, D. (2011): «Los efectos de 'Señorita', el hit más flamenco de Bollywood», Sociedad Gráfica de las Indias, 21.IX.2011, http://www.lasociedadgeografica.com/ blog/espana-en-india/los-efectos-de-senorita-el-hit-mas-flamenco-de-bollywood/ [consultado el 15/12/13]

MAZóN, D. (2011): «Boolywood más flamenco que nunca», La Razón Digital, 14.X.2011, http://www.larazon.es/detalle_hemeroteca/noticias/LA_RAZON_391423/5106bollywood-mas-flamenco-que-nunca\#.UtEfYfTuLTo [consultado el 17/12/13]

McKee, R. (2009): El guión. Sustancia, estructura, estilo y principios de la estructura de guiones, Barcelona, Alba Minus.

MÉndiz, A. (2011): «Emplazamiento de ciudades en el cine ('City Placement'): una estrategia de doble sentido entre la producción cinematográfica y la industria del turismo», III Congreso Internacional Latina de Comunicación Social: La comunicación pública secuestrada por el mercado. 5-9 de diciembre de 2011 (Tenerife). [Actas: http://www.revistalatinacs.org/11SLCS/actas_2011_ IIICILCS/094_Mendiz.pdf]

MÉNDIZ, A. (2014): «City placement: Concepto, literatura científica y metodología de análisis», Questiones Publicitarias, vol. I, no 19 (en prensa).

Moya, J. (2010): «'Sólo se vive una vez’, o cómo Alájar baila por Bollywood», Diario de Sevilla, 11.VIII.2010, http://www.diariodesevilla.es/article/ocio/765857/solo/ se/vive/una/vez/o/como/alajar/baila/por/bollywood.html [consultado el 16/12/13]

Navarro, S. (2011): «Bollywood danza con tomates en Buñol», Levante, 4.VII.2010, http://www.levante-emv.com/comunitat-valenciana/2010/07/04/bollywood-danzatomates-bunol/720142.html [consultado el 15/12/13]

Puente, A. (2003): Cognición y aprendizaje: Fundamentos psicológicos, $2^{\mathrm{a}}$ edición, Madrid, Pirámide.

Riley, R. \& Van Doren, C. S. (1992): «Movies as tourism promotion. A 'pull' factor in a 'push' location», Tourism Management, 13 (3), 267-274.

Robledo, J. J. (2011): «La Tomatina, versión Bollywood, que arrasa en India», $B B C$ Mundo, 1.IX.2011, http://www.bbc.co.uk/mundo/noticias/2011/09/110831_ pelicula_tomatina_bollywood_en.shtml [consultado el 13/12/13]

SEgER, L. (2010): Cómo convertir un buen guión en un guión excelente, Madrid, Rialp, $10^{\mathrm{a}} \mathrm{ed}$.

Torres, M. (2010): «España, destino turístico favorito de la India gracias a una película de Bollywood», Agencia Efe: Practica español, 30.VII.2011, http://www. practicaespanol.com/es/espana-destino-turistico-favorito-india-gracias-peliculabollywood/art/5270/ [consultado el 18/12/13] 
Torres, M. (2011): «La Tomatina de Buñol se estrena en Bollywood», Levante, 25.VII.2011, http://ocio.levante-emv.com/cine/noticias/nws-24915-la-tomatinabunol-estrena-bollywood.html [consultado el 13/12/13]

Urieta, V. (2010): «Los Sanfermines se alargan con Bollywood», Diario de Navarra, 17.VII.2010, http://www.diariodenavarra.es/20100717/pamplona/bollywoodpamplona.html?not $=2010071701505992 \&$ dia $=20100717 \&$ seccion $=$ pamplona\&sec cion2=pamplona [consultado el 19/12/13]

Villafañe, J. (1992): Introducción a la teoría de la imagen, $4^{\text {a }}$ edición revisada, Madrid, Pirámide. 